TERRA. Revista de Desarrollo Local

e-ISSN: 2386-9968

Número 9 (2021), 209-215

DOI 10.7203/terra.9.21923

IIDL - Instituto Interuniversitario de Desarrollo Local

\title{
Reseña. Antropoceno, reproducción de capital y comunismo
}

\section{Jorge Bergua}

Graduado en Ciencia Política y de la Administración Pública (Universidad Autónoma de Madrid, España)

berguajorge6@gmail.com

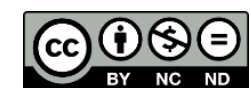

Esta obra se distribuye con la licencia Creative Commons Reconocimiento-NoComercial-SinObraDerivada 4.0 Internacional 


\section{SECCIÓN RESEÑAS}

\section{Reseña. Antropoceno, reproducción de capital y comunismo}

Resumen: Al comienzo de la presente obra, el autor conceptualiza el término Antropoceno desde la premisa de una nueva época geológica en la historia de la Tierra. En ella, sostiene, interaccionan diversas crisis desde dentro del sistema capitalista, fundamentalmente; la crisis secular de valorización del capital. Esta crisis, expone, nos coloca en una situación de emergencia planetaria (afecta simultáneamente a todas las geosferas terrestres), y tiene su origen en el modo de desarrollo y producción extractivista y fosilista, que convulsiona por la mercantilización y la reproducción de capital. Por último, apoyado en el análisis sociometabólico de reproducción del modo capitalista, propone la posibilidad de superar esta crisis a través de la organización de las sociedades que, conscientes de la coyuntura histórica, logren resolver las contradicciones en un planeta que se fractura.

Palabras clave: crisis sistémica, Antropoceno, capitalismo, reproducción de capital, comunismo.

Recibido: 15 de noviembre de 2021

Devuelto para revisión: -

Aceptado: 16 de noviembre de 2021

\section{Referencia / Citation:}

Bergua, J. (2021). Reseña. Antropoceno, reproducción de capital y comunismo. TERRA. Revista de Desarrollo Local, (9), 209-215. DOI 10.7203/terra.9.21923 


\section{Carles Soriano Clemente \\ ANTROPOCENO, REPRODUCCIÓN DE CAPITAL Y COMUNISMO}

Madrid (España). Maia Ediciones, 2021, 246 pp.

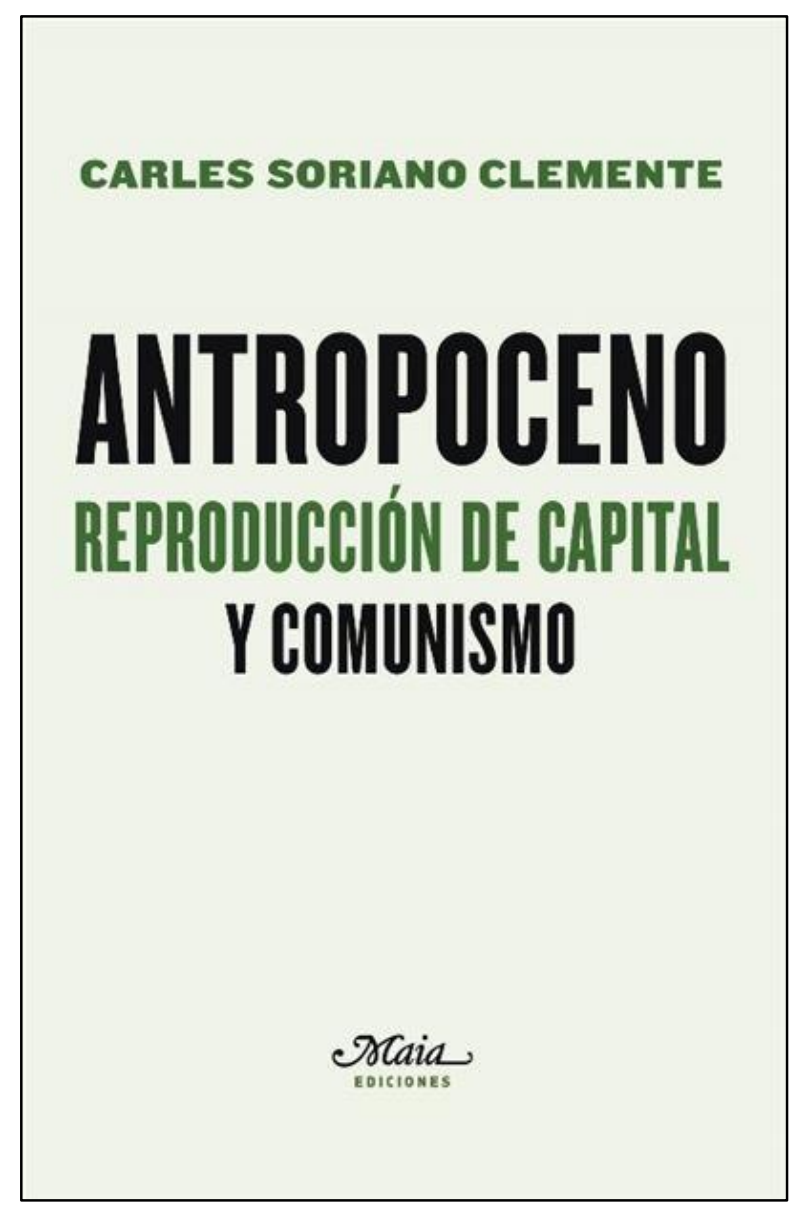

La obra que reseñamos a continuación, traza un recorrido analítico a través de la crisis ecológica y social, acotando, en primer lugar, la forma geológica y cronoestratigráfica del Antropoceno, puntualizando en la alteración de ciclos biogeoquímicos. Seguidamente, incorpora diversos elementos con los cuales analiza, teniendo en consideración los planteamientos de las diversas corrientes marxistas, las características sociometabólicas de reproducción del capital y las leyes económicas de acumulación del capitalismo, el papel del Estado, así como los límites del enfoque del crecimiento económico y el límite estructural de reproducción del capital como paradigma de desarrollo, y sus subsiguientes consecuencias en la forma de crisis demográfica. Propone, en último término, una revisión crítica de la construcción del sujeto capitalista como ser social, del socialismo del siglo XX y del Estado del Bienestar. Consecuencia de ello, expone las diversas posibilidades de transformación y organización consciente de la sociedad, las cuales logren subsanar la fractura metabólica de ésta con la naturaleza.

En el primer capítulo, aborda las causas y consecuencias del Antropoceno (término que cristaliza en el siglo XXI, después de las investigaciones científicas acerca del cambio climático del siglo anterior) como una nueva era geológica de la Tierra en la cual convulsionan diversas crisis sistémicas (desde la atmósfera a la litosfera, pasando por la biosfera y la hidrosfera) con origen antrópico. Toma, como punto de partida, las definiciones de la literatura científica que fundamentan su análisis del Antropoceno en un enfoque transdisciplinar. Éste, mediante un abordaje holístico, busca ampliar y actualizar los estudios sobre el cambio global desde las ciencias naturales y las ciencias sociales "bajo un mismo paraguas epistémico [...] en un armazón teórico y orgánico de conjunto que considere las particularidades metodológicas y analíticas de cada disciplina" (pp.13-45). Estas mismas definiciones, observan el Antropoceno como un proceso histórico de dinámicas diversas en el cual la acción y la interacción humana llevan a cabo transformaciones en los procesos naturales (algunos irreversibles), provocando la aceleración de diversos cambios a nivel global que transgreden límites y ponen en riesgo la estabilidad y resiliencia del planeta, y la existencia humana. 
A continuación, señala diversas evidencias empíricas, rasgos constitutivos de la crisis ecológica -y social-, que permiten hacer una radiografía para lograr una comprensión completa de la dimensión del impacto humano en el Antropoceno. Con ello, busca dar cuenta de cómo un diagnóstico completo de las causas permite la posibilidad de un retrato de la crisis del planeta desde la multiplicidad de factores que interaccionan, retroalimentan y alteran las dinámicas terrestres, reconociendo los diversos parámetros que en momentos específicos de la medición de las distintas variables intensifican unos valores u otros.

En primer lugar, expone la relevancia de indicadores y elementos que fueron centrales en las conclusiones sobre las causas relativas al cambio climático: el impacto en la temperatura y el dióxido de carbono (CO2). Apunta a que esto, en buena medida, se debe a la actividad antrópica de utilización de combustibles fósiles en la industria, el transporte, la ganadería y la agricultura industriales, el uso de fertilizantes de base nitrogenada, entre otros (que aumentan la concentración de gases como metano y óxido nitroso, además del ya mencionado $\mathrm{CO} 2$, así como la presencia de partículas sólidas en suspensión). Conviene en añadir, otros elementos estrechamente vinculados con lo anterior: 1) la acidificación de los océanos (debido al proceso de formación de ácido carbónico (H2CO3)) que afecta a la fijación del carbonato (CO3) disuelto en los océanos en forma de carbonato cálcico $(\mathrm{CaCO} 3)$ y con ello la desaparición de la masa coralina; 2) la concentración de nitrógeno en aguas costeras, debido a la eutrofización de las aguas por la sobreproducción de nutrientes, como el fósforo y el nitrógeno, provenientes del vaciado de acuíferos o de la descarga de aguas fluviales enriquecidas por el uso de fertilizantes de base nitrogenada en la ganadería y la agricultura industriales; 3) la pérdida de masa forestal tropical, incide en la concentración de CO2 atmosférico, debido a la actividad de la industria extractiva o a la ganadería y la agricultura industriales; 4) la destrucción del hábitat de numerosas especies y la pérdida de biodiversidad vegetal y animal, en concreto la fauna de vertebrados, debido a causas antrópicas como la ocupación física del espacio terrestre;5) la desertización; 6) la polución de los acuíferos; 7) variables del tipo socioeconómico propias del modo de vida capitalista (como pasará a explicar más adelante el mismo autor) etc.

En segundo lugar, recoge los resultados de diversos estudios científicos, de corte malthusiano, que evidencian como la actividad humana de los últimos 400 años ha conducido a la sobrepoblación del planeta, excediendo la capacidad de carga del mismo. La población humana, "desde el siglo XVIII ha experimentado un crecimiento exponencial en seis mil millones de individuos, correspondiendo el mayor incremento al siglo XX" (p.24), constituyendo el periodo de la "Gran Aceleración" dentro de la crisis planetaria.

Añade, en tercer lugar, algunas de las objeciones realizadas a la formalización estratigráfica del Antropoceno. Siguiendo la literatura científica especializada, y en palabras del propio autor, estas objeciones parten de una premisa etnográfica y burguesa del territorio, además de dualista del conocimiento geológico ("nomenclatura [desfasada] que deberá resolver la estratigrafía” (p.37)). Son, además, restrictivas con la voluntad de proyección del Antropoceno puesto que ignoran, sostiene, que las ciencias del sistema Tierra tienen un carácter predictivo de escenarios probables.

Siguiendo lo anterior, y a modo de contrarréplica, expone la propuesta realizada por el Grupo de Trabajo del Antropoceno (AWG), que sigue los procesos formales de la Comisión Internacional de Estratigrafía (ICS). Algunos de los argumentos que esgrimen señalan la relevancia del Antropoceno, en cuanto a su manifestación geológica, pues 
este periodo se define cualitativa y cuantitativamente en diversos cambios respecto al Holoceno. Apuntan que la velocidad, la magnitud y la dimensión de los procesos globales desencadenados, en los siglos que corresponden la modernidad, pudiéndose observar el impacto en el registro de la sedimentación antrópica asociado a este lapso de tiempo. Apoya estos argumentos, también en diversas discusiones presentes en el debate científico que cuestionan la tabla de tiempos geológicos y su capacidad para representar el estado de las cosas actual, así como "la vigencia de sus normas y jerarquías" (p. 33), señalando la forma geológica propia de esta crisis planetaria registrada en las rocas. Sostiene, además, la necesidad de incluir nuevos marcadores estratigráficos que enriquezcan la disciplina de la geología. Con ellos, se busca actualizar los estándares de medición a través de la observación de elementos y características socioeconómicas intrínsecas a la intensa actividad e intervención humana en los últimos decenios ("a una forma concreta de lo humano [...] Las contradicciones del modo de producción mercantil y reproducción social capitalista" (p.46-47)) con el desenvolvimiento de este modelo y la forma de organización social vinculada a él. En este punto, incorpora la discusión presente en la literatura científica acerca del uso de los términos Antropoceno o Capitaloceno para designar el periodo histórico contemporáneo.

En este sentido, y observando la correspondencia inmanente entre el modo de organización social capitalista (que tiene su origen en el modo de producción feudal dominante en la Europa medieval) y el Antropoceno, incorpora las contribuciones de las diversas corrientes marxistas (la hermenéutica marxiana) a la discusión acerca de la crisis planetaria. Comienza señalando, algunas de las aportaciones que se hicieron al marxismo, durante el siglo XX, desde el seno de la economía ecológica (el autor puntualiza que "el ecologismo es un producto tardío de la sociedad burguesa" (p.53)), el feminismo marxista, el marxismo descolonial, y otras, las cuales, en cierto modo, han considerado [de forma prematura] los planteamientos de Marx dualistas (leyes de la naturaleza-leyes económicas del capital). El autor, siguiendo la línea de releer críticamente los planteamientos de Marx "como la continuación de esta obra teóricopráctica $[\ldots]$ a través del marxismo crítico constructivo, en una tarea colectiva inacabada" (p.55), también se detiene en señalar los diversos sesgos del reformismo postmoderno. Incide en que los mismos, fueron desarrollados en un contexto histórico en que las ciencias naturales y el estudio holístico del sistema Tierra no habían eclosionado, y, aun con ello, subraya que originalmente buscaron ofrecer también una solución estructural, y no coyuntural. El análisis de Marx del metabolismo social capitalista (la decadencia provocada por el mito prometeico y economicista del desarrollo, a través del análisis del despliegue del capitalismo en la burguesía europea, paradigmático de la sociedad inglesa del siglo XIX), y de la fractura metabólica con la naturaleza, consecuencia del primero, (que violenta el segundo principio de la termodinámica y, en consecuencia, los límites biofísicos del planeta). Esto es, la observación del vínculo estructural entre la degradación de la naturaleza y la reproducción sociometabólica del capital, sobre la base de las herramientas del marxismo "para trazar una salida consciente y perdurable de esta crisis [...] en una época dominada por la atomización social" (p.56).

A continuación, señala el autor la relevancia de la reproducción del capital con relación a la crisis planetaria del Antropoceno, y la manifestación de sus contradicciones inherentes (fundamentalmente la contradicción capital-trabajo), y la categoría central del trabajo: "el trabajo es una categoría universal de la producción social, mientras que la producción capitalista y el capital son categorías históricas” (p. 60). El trabajo es, en 
palabras del propio autor citando a Marx, aquello que produce los medios de vida para los seres humanos y su propia vida material (p. 68), y que media entre el metabolismo de la naturaleza y el metabolismo humano. Éste, depende del modo de producción social y adopta sus formas concretas, quedando la explotación del trabajo (como forma capitalista de apropiación del trabajo) como una determinación propia de las sociedades clasistas. Haciendo posible la enajenación del mundo natural, a través de la división del trabajo como forma del ser social, y del cambio, circulación, distribución y consumo momentos de la producción social (p.69). Para ello, toma de Marx las tres dimensiones del trabajo y del trabajo en el capitalismo, y sus inercias metabólicas con la naturaleza (pues suponen procesos de modificación dialéctico y materialista): 1) en cuanto actividad (señala: el carácter teleológico, el conocimiento y los valores inmanentes del trabajo en su forma social e histórica), 2) en cuanto producto objetivado de la actividad del trabajo (señala: la fuerza de trabajo es un producto del trabajo. El trabajo en la producción mercantil capitalista es mediación del valor), y, 3) en cuanto capacidad/fuerza de trabajo o capacidad de crear excedente de valor (señala: el valor de la misma, vendrá determinado por la media social del tiempo de trabajo necesario para producir los medios de subsistencia que hacen posible las condiciones reproductivas de la sociedad mercantil capitalista, y por ende del capital).

Habiendo abordado la cuestión del capital como mediación histórica, interpuesta entre el trabajo (en tanto mediación del metabolismo social con la naturaleza) y el ser social, expone a continuación el autor los elementos distintivos de la producción del capital y la mercancía, como como unidad reproductiva sociometabólica de la sociedad capitalista, y su mediación en los procesos productivos de la sociedad. Añade, un análisis del comportamiento de la ley de la tendencia decreciente y la serie temporal de la tasa de ganancia capitalista, y las implicaciones que tiene en el Antropoceno las subsiguientes crisis económicas.

Respecto al metabolismo social determinado por la reproducción del capital, y la fractura metabólica (propuesta por Marx en El Capital) globalizada en la forma de circunstancias concretas en el Antropoceno, señala, que el metabolismo capitalista presenta particularidades históricas, así como impone condiciones socioeconómicas concretas. Añade, en virtud de lo anterior, que el metabolismo de las sociedades humanas les supone capacitados para "producir las condiciones materiales de su propia reproducción, que se desarrolla socialmente en función de las particularidades de los modos de producción social históricos" (p. 155). Teniendo en cuenta lo anterior, incorpora la cuestión demográfica, haciendo una lectura de la literatura científica, junto a la gráfica histórica de la población mundial, a fin de dar cuenta de las diferencias cuantitativas y cualitativas entre los periodos precapitalistas y capitalista, y su evolución exponencial ("actualmente en fase regresiva" (p.205)) consecuencia, entre otras, de la utilización de fertilizantes de base nitrogenada en la agricultura y la utilización de combustibles fósiles en la industria ganadera. En suma, en palabras del propio autor "la ley de población capitalista, es la forma demográfica de la ley de acumulación de capital y de la ley de la tendencia decreciente de la tasa de ganancia" (p.181).

Finalmente, el autor expone como la lógica y dinámica de reproducción de capital (y, por consiguiente, la crisis secular de valorización del capital), tienen como producto la contradicción inmanente en el momento concreto de la crisis del Antropoceno. Se evidencia que, los humanos son dependientes de la inmanencia del sustrato natural pero también se enajenan de éste y lo modifican a través del trabajo. De esta dinámica del metabolismo social capitalista, se deriva que la sobreproducción y sobreacumulación de capital profundiza la fractura metabólica con la naturaleza (extralimitación y 
sobreexplotación), que es consecuencia de la sobreaglomeración demográfica. Además, apunta, coincide la expansión del modelo capitalista, durante el siglo XX, con "la era del petróleo barato" (posterior a la etapa keynesiana de la Gran Depresión), que edificó el Estado del Bienestar ("y su posterior fracaso" (p. 223)) a finales del siglo XX, apuntalando el capitalismo neoliberal aun sobre el modelo de capitalismo colonial de la periferia. Al tiempo, se forjaban las resistencias del movimiento social, característico de este mismo siglo y heredero del movimiento obrero del siglo XIX que buscaba responder al antagonismo social de clase estructurales. En este punto, bosqueja, y hace una lectura constructiva, de las limitaciones del socialismo del siglo XX.

Con la obra, en palabras del propio autor, se pretende desentrañar como el conocimiento acerca de las causas de la crisis planetaria característica del Antropoceno, consustancial con el periodo histórico del capitalismo, (en todas sus formas y manifestaciones; los fundamentos del modo capitalista de producción social), es fundamental para poder trazar una solución integral para una salida airosa de la misma. En síntesis, propone el autor la posibilidad de configurar un orden social que organice la reproducción material de la propia sociedad, y que se signifique como antagónico al modo del capital.

Jorge Bergua

Graduado en Ciencia Política y Administración Pública (Universidad Autónoma de Madrid) 